\title{
DA DIFICULDADE DE “CONVERSÃO” À MENTALIDADE GESTÁLTICA ${ }^{1}$
}

\author{
The Difficulty of "Conversion" to Gestalt Mentality
}

De la Dificultad de la Conversión a la Mentalidad de la Gestalt

WALTER FERREIRA DA Rosa RibEIRO

\begin{abstract}
Resumo: O contato diário com a comunidade gestáltica, seu brilho e suas limitações convenceram-me de que para compreender a radicalidade revolucionária da proposta gestáltica (revolucionária para as crenças mais profundas, para as normas e valores culturais encrostados há séculos em nossa Sociedade Patriarcal Europeia e, portanto, em cada um de nós) devemos começar a ter melhor e maior clareza a respeito do quanto essas crenças e esses valores ainda nos governam. Portanto, em que medida eles ainda constituem a nossa mais íntima motivação e, assim, comandam nossas percepções, atitudes, opiniões, emoções, sonhos e ações. Palavras-chave: Autopreservação; Condicionamento Secular; Percepção; Competitividade.
\end{abstract}

\begin{abstract}
The daily contact with the Gestalt community, its brilliance and also limitations have convinced me that to understand the radical ness of the revolutionary Gestalt Therapy's proposal (revolutionary to the established cultural beliefs and values deep ingrained for centuries in our European Patriarchal Society and so in each of us) - we must begin by having more and better understanding of how much these values and beliefs still govern us. So, to what extent these values and beliefs still constitute our inner motives and, thus, command our daily perceptions, attitudes, opinions, emotions, dreams and actions.
\end{abstract}

Keywords: Self-Preservation; Secular Conditioning; Perception; Competitiveness.

Resumen: El contacto diario con la gestalt de la comunidad, su brillo y sus limitaciones me han convencido de que para entender la figura del revolucionario radical (revolucionario para las más profundas creencias, a las normas culturales y valores costra siglos en nuestra sociedad patriarcal y europeos, por lo tanto, cada uno de nosotros) debe empezar a tener una mejor y mayor claridad acerca de cómo estas creencias y valores que estas aún nos gobiernan. Por lo tanto hasta qué punto siguen siendo nuestros más cercanos y por lo tanto la motivación de comandos nuestras percepciones, actitudes, opiniones, emociones, sueños y acciones.

Palabras-clave: Auto-Preservación; Condicionamiento Secular; Percepción; Competición.

“Tudo que é visto, é visto por um olhar" (Merleau-Ponty)

"O terapeuta é seu próprio instrumento" (Polster \& Polster)

A frase singela de Merleau-Ponty (bem como a proposta gestáltica), nos remetendo a nós mesmos, coloca-nos de frente e de cara com problemas muito amplos, delicados e complexos: por exemplo, diante da necessidade de reavaliar com constância aquilo que pensamos que sabemos e, mais ainda, se realmente sabemos quem somos e o que queremos. E, com isso, ter mais clareza sobre as razões de nossas ações, de nosso modo de ser-estar-no-mundocom-os-outros, sejam esses outros pais, filhos, cônjuges, clientes, nós mesmos, qualquer "outro" ou a Sociedade da qual somos partes inalienáveis.

\footnotetext{
Texto originalmente apresentado no I Encontro Candango da Abordagem Gestáltica, no Fórum "A Relação Terapeuta-Cliente e o Processo Psicoterápico”, Brasília, 02 de outubro de 2004 (Revisto e atualizado em maio de 2007 e outubro de 2009). Meus agradecimentos às psicólogas, Malu, Irma, Suzana, Denise e Maria Célia, pelas preciosas correções e sugestões oferecidas durante nossa leitura conjunta da última atualização.
}

Assim, mais de quarenta anos depois que iniciei minha primeira terapia com José Ângelo Gaiarsa, ainda me estou clarificando sobre meus motivos e o meu estilo de olhar ou de ser-estar-no-mundo-com-os-outros. Não é fácil engolir este fato!

Acredito que sempre me perturbei com certa facilidade com o que os meus olhares "viam". Quero compartilhar uma velha perturbação que insiste em povoar meus sonhos de profissional, tentando não cair na tentação de aplacá-la com alguma resposta apressada e prematuramente pacificadora, tarefa difícil em nossa cultura centrada em "problemas" e ansiosa por "resolvê-los".

É a partir desse limbo de incertezas e de buscas que trago alguns desencontros e achados que tenho tido com a nossa teoria e, principalmente, com a nossa prática, (obviamente nos seus e meus estágios de desenvolvimento de cada encontro), nessa minha sempre inacabada caminhada de aprendiz pretensamente "experiente" desse universo tão amplo e abrangente a que chamamos Gestalt-terapia, e principalmente, do extenso e dinâmico contexto filosófico/científico/ artístico no bojo do qual ela surgiu e no qual inevitavelmente nos inserimos e podemos melhor caminhar 
se estivermos atentos ao seu também incessante movimento e ampliação.

Julgo essa minha preocupação não excessiva se considerarmos o quanto a proposta gestáltica ainda é perturbadora ao sugerir um modo de ser-e-de-estar-no-mundocom-os-outros diametralmente oposto ao modo patriarcal/ conservador, onde estamos instalados há milênios e onde, portanto, vimo-nos co-construindo, sendo adestrados e adestrando (Stein, 2009), sendo condicionados e condicionando, estilo de ser/estar exaustivamente observado na experiência clínica de qualquer profissional atento.

A proposta gestáltica (bem como a de todas aquelas que se alinham e se colocam do outro lado da prepotência imperante) propõe-nos, neste contexto adverso de nossas existências, uma tarefa ou missão extremamente difícil e até mesmo quase impossível. Em primeiro lugar, entender uma proposta radicalmente democrática da qual não temos vivência ou referência e, depois, o mais difícil ainda: tornarmo-nos democratas radicais e agirmos de acordo diante dos outros, do mundo e de nós mesmos. Ou seja, negar (ou transcender?) a nossa própria condição penosamente constituída de seres que mais se defendem e atacam do que confiam, o que fortemente sugere que a nossa formação deu-se e se dá em contextos pouco favoráveis ao desenvolvimento individualizado, diferenciado e livre.

Para nos autopreservarmos nesses contextos, essa negação pode levar-nos (e nos tem levado) a modos de ser fingidos e hipócritas ou a desenvolver características como as descritas por Sartre como "má-fé” ou que Heidegger denominou, em suas reflexões, como "o modo de ser cotidiano" (provavelmente, a partir de "representações" historicamente criadas, desenvolvidas e consolidadas por meio de percepções distorcidas como as que Platão descreveu na metáfora da Caverna). Comportamento claramente movido e motivado pela necessidade de instituir alguma ordem, de ter alguma opinião sobre a complexidade ou o caos do existente com o objetivo de melhor sobreviver (Deleuze \& Guattari, 1992).

É óbvio, portanto, que não há culpa de ninguém nesse processo, já que desde sempre tivemos que nos autopreservar e sobreviver em contextos nutritivos e tóxicos, além de ambíguos, dissimulados e geralmente cheios de manhas e de disfarces.

Como esse contatar com o contexto e consigo mesmo (portanto, com o campo total) é permanente, absoluto, abrangente e inquestionável, torna-se determinante na direção do posicionamento de cada um e do seu funcionar consigo mesmo, com os outros e com o mundo, ou seja, na determinação do estilo dos seus ajustes, do seu modo de existir. E, claro, de entender o processo clínico e na determinação do seu modo de ser/estar com o outro com a intenção e a pretensão de ajudá-lo a reencontrar-se.

Perceber com clareza crescente essa dinâmica de mútua formação/deformação na qual estamos imersos (e suas consequências) é a tarefa que percebo como proposta central da "mentalidade gestáltica" (Perls, Hefferline \& Goodman, 1994) para, então, e só então, definir o como das relações que poderíamos chamar de "facilitadoras" ou de "obstrutoras/dificultadoras" ou mesmo desviantes do fluxo existencial livre ou, ainda, condicionadoras/adestradoras. Dito de outra forma, pensar em que direção nosso "fazer” nos está levando: para a manutenção, desenvolvimento, sofisticação e perpetuamento de nossos mútuos adestramentos ou para o outro lado, o lado da busca da liberdade e do humano, que nos leva à aceitação e desenvolvimento de nossas singularidades e ambiguidades de seres únicos, irrepetíveis e imprevisíveis.

Michael Vincent Miller e Isadore From utilizamse, na sua apresentação do Gestalt Therapy (Perls et al., 1994), da metáfora de dois modos opostos de ser-estarno-mundo-com-os-outros e do estilo de ação que prevalece em cada um deles: o "cara-pálida” - onde predomina o intelectualismo, o conceitualismo, a fala falada ou segunda (Merleau-Ponty, 1974, 1994; Amatuzzi, 1989); e o "pele-vermelha”, em que a ação pronta e rápida, a la John Wayne, é suportada por pequena, intolerante, rígida e superficial base teórica; ou seja, quando nossa condição de ingênuos representantes de uma determinada cultura é mais clara e evidente.

Paulo Freire, em "bate-papo" com um grupo nacional de gestalt terapeutas, na década de 80, sugere-nos a busca do equilíbrio entre o pensar e o fazer (fazendo referência às nossas duas pernas), quando acrescenta, no seu delicioso pernambuquês: "quem só pensa é um masturbador mental... e quem só faz é um porra-louca!....".

A partir das concepções, ensinamentos e dúvidas desses e de outros mestres, tento sempre me esclarecer como venho percebendo a trajetória da Gestalt-terapia nesses quase quarenta anos em que tento entendê-la e evoluir com ela. Ou, talvez melhor, tento ter permissão para que ela faça parte do meu devir.

O tema deste "Fórum" remeteu-me de novo à nossa história e, portanto, à grande e velhíssima revolução ontoepistemológica reativada e recrudescida há 100 anos (ainda ativa e acirrada até hoje) na Filosofia, nas Ciências e nas Artes. Revolução que, acredito cada vez com mais firmeza, ter sido a mais forte e consistente rebelião contra os dogmas do Patriarcalismo que submeteu nossos ancestrais europeus há seis ou sete mil anos (Maturana \& Verden-Zöller, 2004).

O espaço e o tempo de maior ebulição dessa tentativa de reviravolta cultural, de mudança radical de paradigma, foi o início do século XX, notadamente na Alemanha, onde se alimentava e florescia o jovem casal Perls: Lore (Laura) e Frederick (Fritz).

Não havia nenhum setor da vida cultural alemã que não estivesse contaminado por esses ares insatisfeitos e renovadores - como acentuou Merleau-Ponty (1974), em seu Ciências do Homem e Fenomenologia -, por esse an- 
seio de libertação dos velhos padrões e paradigmas patriarcais/matriarcais. Fundo abrangente onde o casal respirava, bebia, se nutria, aprendia e se formava.

Como não poderia deixar de acontecer, esses ares de renovação e de liberdade provocaram e entraram em choque com as forças mais conservadoras e prepotentes do milenar patriarcalismo no qual ainda estavam/estamos imersos. Imersão que infelizmente ainda nos tolhe e incomoda existencialmente mais do que podemos perceber racionalmente.

A nova proposta desequilibrava em demasia (e ainda o faz) a luta de contrários [no caso, entre a Prepotência, a compulsão de dominação, de submissão e de uso (suportes de qualquer cultura hierarquizante como a patriarcal européia ou a dos caçadores de cabeça, de Margareth Mead, por exemplo)]. Exagero da luta de contrários que leva à des-confiança e à desqualificação do outro, do diferente, do proponente de novidades, visto como um inimigo inferior a ser subjugado ou eliminado. Crença e postura que se opõe visceralmente, de corpo e alma, à proposta realmente democrática, liberadora, de aceitação das diferenças, de solidariedade, de aceitação da sabedoria organísmica (Perls, 1977) do outro que, assim, passa a ser um legítimo outro. Talvez parceiro, talvez não. Porém, equalizado e legitimado em suas opções. Acredito que a cultura "Matriztica" existente na Europa antes das invasões bárbaras (Maturana \& Verden-Zöller, 2004; Maturana \& Rezepka, 2008), bem como a cultura dos plantadores de inhame (Mead, 2003) são exemplos desse tipo de postura perante o outro, perante a Natureza e perante si mesmo.

A luta de contrários é inerente a tudo, como já apontou Heráclito há 2.400 anos, quando diz:

(...) o nascimento e a conservação dos seres devemse a um conflito de contrários que, mutuamente, se opõem e se mantêm, (...) limitando-se e se unindo, em harmonia e em discordância (...) Todo excesso de um contrário que ultrapasse a medida é punido pela morte e a corrupção (Heráclito, citado por Bréhier, 1948, p. 56).

Bateson (1986) também diria, depois de 24 séculos: "nem um total conservadorismo nem uma completa ansiedade pela mudança são apropriados” (p. 228).

A convivência tão pacífica quanto possível dos contrários, sem a ingênua pretensão de subjugação ou da eliminação do outro parece ser o grande dilema humano. Sempre considerado e enfrentado por poucos e sempre escamoteado, negado e distorcido pela maioria não contestadora, comodista, conformista e fortemente interessada em progressos racionais/materiais.

No caso da Alemanha do início do século passado, os contrários à postura, à mentalidade liberadora proposta, ou seja, a elite do poder conservadora e radical, assim provocada e ameaçada, colocou Hitler no poder, e Hitler matou, ou pôs para correr, praticamente toda aquela elite intelectual indesejável para o seu patriarcalismo prepotente.

Como tantos, os agora casados Lore e Fritz fugiram para a Holanda, dali para a África do Sul e de lá para Nova Iorque. O grande contestador e intuitivo Fritz - acredito que também fortemente influenciado por Nietzsche e Bergson -, continuaria sua busca por novos ares de mais liberdade: quando faleceu apostava todas as suas fichas no sonho de Cowichan, fazendo-nos crer que sabia muito bem que só em ambientes, contextos, campos mais amenos e solidários, os conflitos podem vir à tona e serem examinados, considerados e amorosamente tratados em busca não da eliminação dos contrários, mas em busca da melhor integração criativa possível no aqui-e-agora em que acontecem. Não importando se os conflitos estão acontecendo nas relações comigo mesmo, com os outros ou com o Mundo.

Fiz essa viagem com vocês para exemplificar de dentro, e a partir da nossa própria história, bem como para termos consciência cada vez mais clara, de que qualquer ar de liberdade tem sido e é sentido como veneno letal para corpos, mentes e espíritos poluídos por séculos de conservadorismo exacerbado, do autoritarismo adestrador por nós sofrido por tanto tempo e que nos formou/ deformou e do qual, portanto, somos, com consciência ou fora dela, representantes e perpetuadores. Cada um de nós, é claro, com o seu próprio grau de crença e de imersão nessa cultura anti-indivíduo, cultura que vê o nosso anseio de buscar e de desenvolver a nossa diferença, a nossa busca de individualidade e de singularização, como ofensa e ameaça direta à sua segurança, à sua continuidade, à sua sobrevivência.

Obviamente, os mais jovens dentre nós (as crianças, principalmente) têm mais possibilidade de se descondicionarem ("somos seres condicionados, mas não determinados" - diria Paulo Freire), de se libertarem desse modo de ser prepotente e centrado no "êxito" a qualquer custo, dessa eterna busca de poder e de dominação que alimenta a competitividade desenfreada e desumanizante tão solidamente instalada e que nos mantém a todos (dominadores e dominados, "top dogs" e "under dogs") fatalmente agrilhoados à sua guerra sem fim.

Crescentemente, os cientistas de ponta (praticamente de todas as ciências), bem como a Filosofia, acreditam que a busca do dinâmico, instável e fugidio equilíbrio entre opostos é muito mais abrangente, complexa e difícil do que ingenuamente imaginávamos.

Como velho e apaixonado aspirante a gestaltista, gosto de exemplos práticos, de experimentos ou de analogias que tragam para a vida aquilo de que falamos e teorizamos no lá-e-então do pensamento "sobreista" que nos nutriu e nutre. Vou citar um experimento talvez chocante demais, mas elucidativo para a necessidade gestáltica de entender "a naturalidade" e de respeitar as peculiaridades únicas da formação de cada ser, ser que, sabemos, co-constrói-se 
com contextos cujas especificidades moventes também não podem ser negadas:

Recentemente, relendo As Três Ecologias, de Félix Guattari (1990), deparei-me, com o seguinte:

Experimento de Alain Bombard na televisão: apresentou duas bacias de vidro, uma contendo água poluída como a que podemos recolher no porto de Marselha e na qual evoluía um polvo bem vivo, como que animado por movimentos de dança; a outra, contendo água do mar isenta de qualquer poluição. Quando ele mergulhou o polvo na água “normal”, após alguns segundos, vimos o animal encarquilhar, se abater e morrer (p. 25).

Perdoem-me a violência, mas não pude deixar de pensar na analogia desse experimento com as dificuldades facilmente observáveis em todos nós de deixar a água poluída de nossa cultura, onde prevalecem a luta pelo poder e pela dominação, a confusão do material e do espiritual, o desamor, o adestramento, a competitividade desenfreada, a prepotência, a coerção e o inevitável narcisismo, como se fôssemos o polvo que "se encarquilharia, se abateria e morreria” na água limpa da solidariedade, da ética, do amor, da democracia (a verdadeira: utópica?) e do sentimento de respeito para com o diferente, o novo, o inusitado; água certamente proposta pela "mentalidade gestáltica... a abordagem original, não deturpada e natural da vida" (Perls et al., 1994) e pela mentalidade de todos aqueles que voltaram a insistir, no início do século passado (o que os adeptos da sua postura continuam a fazer), nessa proposta existencial que prioriza o humano como alternativa à prepotência da não natural, mas milenarmente instalada, cultura que prioriza a hierarquização, a dominação e o culto aos velhos dogmas instituídos e enrijecidos.

Sabemos que na Alemanha hitleriana os proponentes dessa postura foram exterminados ou escorraçados. As nossas rejeições (exógenas e endógenas) hoje podem ser mais sutis e sofisticadas, disfarçadas, dissimuladas ou até hipócritas, mas não menos eficazes e poderosas como forças de coerção.

Por outro lado, é humano, é justo, é inevitável que nos defendamos e aos nossos condicionamentos, preconceitos, crenças e mesmo deformações: eles fazem parte de nós, nós somos eles, somos o resultado de nossas co-construções com os contextos vividos (a nossa água). Desde os mais longínquos ancestrais até cada um de nós em nossa própria jornada iniciada no ato conceptivo e que continua até hoje, estamos imersos (imiscuídos) com nossos contextos. Somos eles. A Física Quântica está “descobrindo" essa Unidade: "O que a Física Quântica está começando a descobrir é que sua mente está ligada com o Cosmos e se você começa a pensar de uma forma, começa a modificá-lo" (Heriot, 2006).

Não temos referência prática de outras possibilidades existenciais (exceto raríssimos exemplos) de outros modos de viver e de interagir, já que estamos imersos há pelo menos sete séculos nessa cultura (como o polvo em sua água poluída), agrilhoados como os personagens da metáfora da caverna de Platão. É, portanto, difícil até mesmo imaginar como seriam nossas relações em sociedades que realmente priorizassem o humano, o que seria a "vida viva" (segundo Dostoiéwsky), "a abordagem original, não deturpada e natural da vida" (Perls et al., 1994, p. 32). Muito provavelmente, não saberíamos sobreviver sem jogos, sem luta por dominação nas mínimas coisas, sem manhas, manipulações ou fofocas, sem a endêmica (indispensável?) "má-fé” e etc. E, se soubéssemos, onde iríamos viver desse jeito? Não nos esqueçamos de que Sócrates optou por beber a cicuta diante da possibilidade de fuga para outro lugar, onde, pensava, haveria menos liberdade do que na sua Atenas, que o condenara à morte "por corromper a juventude".

Clara e conscientemente, estou-me justificando, justificando meus mestres, meus pares e todos vocês que me ouvem ou lêem por ainda não termos tido condições nem “prontidão caracterológica” para entender a radicalidade democrática da proposta gestáltica. Mais ainda, de ainda não termos condições emocionais e espirituais, e nem mesmo racionais, de vivê-la e, assim, de aplicá-la com a aceitação plena e amorosa das nossas desconcertantes diferenças, das singularidades, por vezes aberrantes ou até assustadoras para o nosso conservadorismo, para a nossa defensividade: nosso defensivo Narciso ferido e desconfiado ainda não pode permiti-lo. Defrontamo-nos, a todo momento, com essas diferenças em nosso quotidiano existencial, talvez mais ainda em nosso trabalho. É extremamente difícil ou até impossível entendê-la apenas racionalmente e a partir de paradigmas epistemológicos e de subjetividades diametralmente opostos. É muito pior do que nadar contra uma forte correnteza.

Quero, ainda, sem paradoxo, parabenizar-nos e a toda a comunidade gestáltica pelo empenho que temos demonstrado em tentar entender a nossa abordagem a partir de "territórios" e de subjetividades tão inóspitos e avessos à sua vocação solidária e libertária.

É com esse espírito, e acreditando em nossas forças e determinação, que estou insistindo que nos detenhamos com maior empenho na clarificação crescente dessa mais ampla luta de contrários, muito mais profunda, difícil, abrangente e complexa do que a luta entre "caras pálidas" e "peles vermelhas", genialmente referida por Michael Vincent Miller e Isadore From na sua Introdução ao Gestalt Therapy (Perls et al., 1994). Luta também ainda viva e atuante porque é muito difícil e ameaçador equilibrarmo-nos na ambígua e tênue linha divisória, no verdadeiro fio de navalha que divide/une os contrários, sem despencar para um lado ou para o outro, como tanto acontece em nosso cotidiano.

Pessoalmente, tenho-me batido muito contra os "Johns Waynes" da "Gestalt" (inclusive contra o pele vermelhismo” do próprio Fritz Perls, em Esalen). Mas o para mim 
excessivo e crescente intelectualismo (conceitualismo, representacionismo) que tenho visto, notadamente nos últimos congressos, está-me levando a ter cuidado com o fortalecimento demasiado do "cara palidismo" na Gestaltterapia, tão grandioso, prepotente e desrespeitador quanto o seu contrário, "o pele vermelhismo”: "qualquer excesso de um contrário...”, já dizia Heráclito.

Se extinguirmos todo o nosso "pele vermelhismo", deixaremos de ser uma Gestalt, a abordagem holística que somos e que visa a integração criativa de todos os componentes humanos: físicos, psicológicos, intelectuais, emocionais e espirituais. A nossa consciência é encarnada, é holística e não platônica ou cartesiana. O Ser Bruto, Selvagem, pré reflexivo (como diria MerleauPonty) percebe e opera em territórios fora do alcance de nosso ser apenas racional sobrecarregado por séculos de entulho cultural. O "fluxo de awareness", da Gestaltterapia, claramente inspirado na "intuição da duração", de Bergson - não é acessível aos lentos processos dissecatórios racionais.

O cruel experimento citado por Guattari serve para nos alertar e termos mais amor, cautela, cuidado e prudência com nossa atitude e ação diante de qualquer luta de contrários, de qualquer comportamento "desviante", onde cada lado vê a adaptação "na marra" (violenta ou sutilmente) ou a aniquilação do outro, como solução "do problema”. Como apontam Perls et al. (1994), mostrandonos e advertindo-nos sobre a crueldade inútil, ingênua e perigosa que poderíamos cometer se tivéssemos o poder (que felizmente é ínfimo) de descontextualizar nossos semelhantes e a nós próprios. "A Verdade Liberta" é o nome de um dos últimos livros de Alice Miller. Precisamos, entretanto, acrescentar que ela pode ser extremamente dolorosa e não nos esquecermos de que, frequentemente, a dor é tamanha que saudavelmente a evitamos com todas as nossas forças.

É por isso que a Gestalt-terapia respeita e trabalha com as "resistências" e não contra elas. Acredita que " $a$ lei básica da vida é auto-preservação e crescimento" (Perls et al., 1994, p. 5).

Tirar-nos abruptamente, ou mesmo com sutileza e aparente amor, de nossa água mãe e nos submergir em outra previamente considerada "despoluída" ainda é a proposta de muitos "ajudadores", trabalhos clínicos e da maioria de nossos sistemas "educacionais", ainda excessivamente submersos e prisioneiros, com ou sem consciência, dos valores e das crenças de nossa cultura madrasta.

Talvez a maior dádiva que a prepotência do patriarcalismo europeu tenha nos legado tenha sido propiciar o desenvolvimento dessa resistência organísmica sabiamente desenvolvida como resposta à sua tirania durante os milênios que temos vivido sob o seu jugo.

Negar, esconder, fazer de conta que a luta de contrários inexiste e, pior ainda, negar que uma vez imersos nela, defendendo um dos contrários em oposição, nos torna sectários fanáticos e perigosos não só para os outros, mas também para o mundo e para nós mesmos.

Felizmente, as mais recentes descobertas das ciências contemporâneas as aproximaram de nossa postura, de nossa "mentalidade" ou "subjetividade". A descoberta e a aceitação da complexidade e da riqueza de qualquer objeto de estudo as obrigou a abandonar o "Princípio da Certeza", o grande suporte teórico e de crenças para qualquer prepotência e autoritarismo, e a adotar o Princípio da Incerteza que nos torna mais cautelosos, modestos, prudentes e até humildes diante da sabedoria da Natureza e da Vida, tornando-nos mais próximos da "mentalidade gestáltica... abordagem original e natural da vida".

Perdoem-me, mais uma vez, pela insistência em compartilhar o temor que o poder desproporcionalmente crescente de um dos nossos contrários, o intelectualismo (na Gestalt-terapia, o “carapalidismo”) está assumindo. Mais ainda, e principalmente, perdoem-me por insistir na dolorosa necessidade de conscientização e awareness dessa muito mais ampla, profunda e complexa luta de contrários entre a ânsia (percebida ou não/consciente ou não) pela manutenção e desenvolvimento do poder controlador e hierarquizante que tem regido e rege nossas vidas e sociedades ocidentais versus a proposta, diametralmente oposta, de recuperação/resgate da convivência amena, pacífica, amorosa e de mútua confiabilidade, que nossos ancestrais fruíam antes da invasão da Europa pelo patriarcalismo bárbaro há seis ou sete mil anos. (Maturana \& Verden-Zöller, 2004; Maturana \& Rezepka, 2008).

O que mais nos dificulta buscar sempre e incansavelmente um equilíbrio maior de forças, e até perceber onde estamos em cada momento desta busca, é a nossa também milenar atração pelo maniqueísmo: ou somos isso OU aquilo; jamais isso E aquilo. Postura que nos leva à tendência de negar a saúde da heracliteana luta de contrários interdependentes e de, rigidamente, tomar partido tanto em querelas insignificantes como em questões de vital importância.

Assumidamente, pertenço ao clube dos inveterados otimistas/românticos (o ceticismo sempre desperta em mim o pior lado, desidratando-me, tornando-me frio, seco e "patriarca"). Entretanto, ou por isso mesmo, tenho tentado ser um otimista de pés fincados no chão, fundamentado em observações, pesquisas e busca constante da essência da Gestalt-terapia.

Espero ter conseguido transmitir a fé profunda que tenho na Gestalt-terapia e no seu paradigma de aprender e de ensinar que tenta captar o método da Mãe Natureza e da Vida, o que nos reconduz à fé no humano e na sua capacidade de comunicação que habita todos nós, mesmo que soterradas por mais de vinte séculos de adestramento, embora eu também esteja convicto (com Maturana e outros) de que a poluição adestradora exercida pela prepotência de nossa cultura patriarcal seja mais antiga do que Stein registrou. 
Insistindo: embora seja inegável que o paradigma gestáltico já habite em nós (por ser “natural”), não paradoxalmente o acesso a ele não é fácil, como temos testemunhado ao rever nossa História bem como nosso próprio comportamento. Também nos repensando com ajuda de outros buscadores, vejo que sozinhos é quase impossível. Há muito entulho, condicionamentos/adestramentos milenares, poluição e mesmo má fé a considerar e até a respeitar nessa jornada. Assim, a luta é mais árdua do que os românticos ingênuos ou os afoitos interessados/ interesseiros teimam em acreditar, embora possa ser ganha com amor, tempo, carinho, prudência, respeito, muita garra e humildade.

Termino este trabalho com a questão crucial que ele expõe e que está no âmago da questão clínica: como Sartre e Heidegger exaustivamente escrutinaram, o Ser Humano faz o que pode para constituir-se (para "autopreservar-se e crescer”) em seus contextos existenciais, não deixando espaço, portanto, para qualquer julgamento. Ambos insistem em que a "má-fé" (Sartre, 2005), o "falatório", a "curiosidade", a "decadência" - modos de ser na "cotidianidade" do Ser-aí (Heidegger) - são "tendências constitutivas do exercício concreto da existência" (Heidegger, 2005, p. 323), pertencendo, pois, ao âmbito da facticidade. Meus aplausos e agradecimentos.

Entretanto, a pessoa concreta à nossa frente não está feliz e sofre em função dos conflitos (percebidos ou não) que vive. Geralmente, está vivendo o lento e penoso processo de clarificação de conflitos e/ou incongruências entre a concretude de sua cotidianidade e a realização de sonhos, e até mesmo de ter entrado em contato (também percebido ou não) com alguma possibilidade de existência mais plena/fluida/feliz e, assim, mais condizente com sua humanidade.

\section{Referências}

Amatuzzi, M. M. (1989). O Resgate da Fala Autêntica. Campinas: Papirus.

Bateson, G. (1986). Mente e Natureza - A Unidade Necessária. Rio de Janeiro: Ed. Francisco Alves.

Bréhier, E. (1948). Histoire de la Philosophie. Paris: Presses Universitaires de France.

Deleuze, G. \& Guattari, F. (1992). O que é a Filosofia?. São Paulo: Editora 34.

Guattari, F. (1990). As Três Ecologias. Campinas: Papirus.

Heidegger, M. (2005). Ser e Tempo. Petrópolis: Vozes.

Heriot, D. (Diretor) (2006). O Segredo [DVD]. Austrália/EUA: Prime Time Productions.

Maturana, H. \& Rezepka, S. N. (2008). Formação Humana e Capacitação. Petrópolis: Vozes.
Maturana, H. \& Verden-Zöller, G. (2004). Amar e Brincar Fundamentos esquecidos do humano. São Paulo: Palas Athena.

Mead, M. (2003). Sexo e Temperamento. São Paulo: Perspectiva.

Merleau-Ponty, M. (1974). Ciências do Homem e Fenomenologia. São Paulo: Saraiva.

Merleau-Ponty, M. (1994). Fenomenologia da Percepção. São Paulo: Martins Fontes.

Miller, A. (1997). O Drama da Criança Bem Dotada. São Paulo: Summus.

Miller, A. (2004). A Verdade Liberta. São Paulo: Martins Fontes.

Pacheco, J. (2008). Escola da Ponte: Formação e Transformação da Educação. Petrópolis: Vozes.

Perls, F. S. (1977). Gestalt Terapia Explicada. São Paulo: Summus.

Perls, F. S.; Hefferline, R. \& Goodman, P. (1994). Gestalt Therapy. Excitement and Growth in the Human Personality. New York: The Gestalt Journal Press.

Polster, E., \& Polster, M. (1974). Gestalt Therapy Integrated Countours of Theory \& Practice. New York: Vintage Books Edition.

Sartre, J. P. (2005). Ser e Nada. Petrópolis: Vozes.

Stein, E. (2009). Antropologia Filosófica - Questões epistemológicas. Ijuí, RS: Ed. Unijui.

Walter Ferreira da Rosa Ribeiro - Psicólogo e um dos pioneiros da Gestalt-terapia brasileira. É fundador e coordenador do Centro de Estudos de Gestalt-terapia de Brasília (Cegest). Endereço Institucional: SHLN, Bloco K, Centro Clínico Norte I, sala 111. Brasília, DF. Email: cegest@cegest.org.br

Recebido em 10.06.09 Aceito em 20.08.09 